\title{
Modular 3D Printed Compressed Air Driven Continuous-Flow Systems for Chemical Synthesis
}

\author{
Matthew R. Penny ${ }^{[a]}$, Zenobia X. Rao ${ }^{[a]}$, Bruno Felício Peniche ${ }^{[b]}$, Stephen T. Hilton ${ }^{[a] *}$ \\ Dedicated to Professor Keith Jones on the occasion of his retirement.
}

\begin{abstract}
In this present study, we describe the development of a low-cost, small-footprint and modular 3D printed continuous-flow system that readily attaches to existing stirrer hotplates. Flow-rates are controlled by compressed air that is typically present in all fume hoods, making it suitable for use by synthetic chemists. The length of the flow-path and reaction residence time is regulated by control of the air-flow and pressure and by addition of one or more 3D printed polypropylene (PP) circular disk reactors that were designed to fit a DrySyn Multi-E base which is found in most synthetic laboratories. The ease of use of the system, the facile control of flow-rates and the solvent resistance of the PP reactors was demonstrated in a range of $\mathrm{S}_{N} \mathrm{Ar}$ reactions to produce substituted ether derivatives highlighting the utility and modularity of the system.
\end{abstract}

\section{Introduction}

3D Printing and continuous-flow chemistry are two emerging and developing technologies that have both grown rapidly over the last decade due to the clear and obvious benefits of each requisite technology. ${ }^{1,2}$ However, whilst 3D printing has expanded rapidly across the sciences in both academic and industrial laboratories becoming an embedded tool of choice for most scientists, ${ }^{3-7}$ continuous flow chemistry despite its obvious advantages, has lagged behind in adoption by synthetic chemists and remains less widely used due to the high costs of the continuous flow systems themselves and their associated reactors and equipment, making it affordable to only a very few academic and industrial laboratories, limiting its acceptance and use amongst synthetic chemists. ${ }^{8}$ In contrast, 3D printing has become an affordable tool to most scientists with rapid falls in the costs of the machines, with fused deposition modelling (FDM) and stereolithography (SLA) printers typically costing around $\$ 3000$, enabling an array of materials to be employed and used in the creation of bespoke equipment. ${ }^{2,3}$

As a result of the high cost of continuous flow reactors and the complex geometries required for efficient mixing, synthetic

[a] Dr M.R. Penny, Miss Z.X. Rao, Dr S.T. Hilton

Department of Pharmaceutical and Biological Chemistry, UCL

School of Pharmacy, 29-39 Brunswick Square, London, WC1N 1AX

United Kingdom. E-mail: s.hilton@ucl.ac.uk

http://www.stephen-hilton.com

[b] Mr B. Felício Peniche

Faculdade de Farmácia da Universidade de Lisboa

Av. Prof. Gama Pinto, 1649-003 Lisboa, Portugal

Supporting information for this article is given via a link at the end of the document chemists have employed 3D printing as a useful tool with which to create bespoke reactors and equipment for use in continuous flow chemistry. ${ }^{2-7}$ Cronin has pioneered the concept of "reactionware" in the field of 3D printing with automated control and delivery of reaction components and accurate control over reagent addition. ${ }^{9}$ Other researchers have also demonstrated how 3D printing can aid continuous flow chemistry with Christie having developed a reactor which can be integrated with an HPLC for facile product detection, ${ }^{10}$ whilst Kappe has reported the use of 3D printed steel reactors for continuous difluoromethylation. ${ }^{11}$ Research in our group has previously focussed on the use of $3 \mathrm{D}$ printed reactors, with the development of polypropylene (PP) column reactors which can be readily integrated with existing flow reactors and are applicable to a range of reactions. ${ }^{12}$ However, a key drawback of all of these approaches are the costs of the flow reactor systems themselves which typically cost upwards of $\$ 20,000$ representing a large barrier to entry for most synthetic chemists into this powerful emerging technology.

As a result of our previous reports on continuous flow synthesis and our development of low-cost equipment across a range of disciplines using $3 \mathrm{D}$ printing, ${ }^{12-13}$ we were intrigued by the possibility of developing a full continuous flow system using 3D printing which could be readily used by synthetic chemists and low enough in cost to be within reach of most laboratories. In addition, we wanted a system with a small size footprint that could be integrated with existing laboratory equipment and removed and stored when not needed, stopping the typical blocking of fume cupboards encountered with most continuous flow systems. Herein, we now wish to report on the results of our approach, which was designed to be integrated with existing commercial stirrer hotplates which are found in nearly every synthetic chemistry laboratory fume hood and the planned design of the system is shown below (Figure 1).

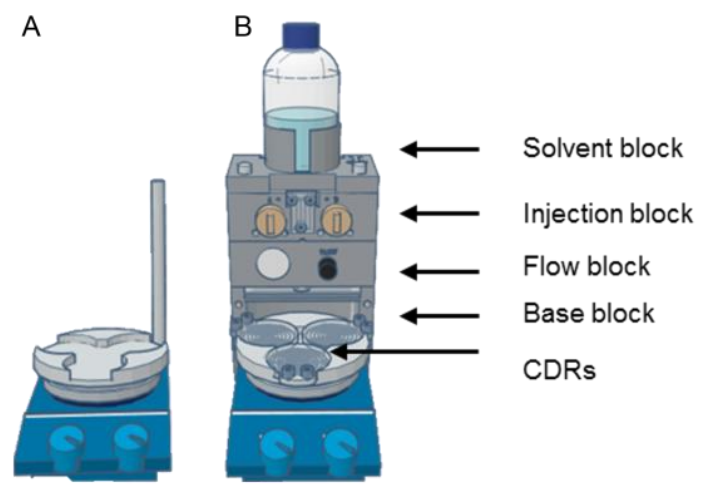

Figure 1. A) Stirrer hotplate with DrySyn Muti-E base; B) Planned System attached to stirrer hotplate incorporating 3 circular disk reactors. 


\section{Results and Discussion}

Stirrer hotplates are found throughout synthetic laboratories and were also selected as they could serve as a heating source for the reactor reducing overall costs. In addition we wanted to use the DrySyn Multi-E base to enable facile lengthening or shortening of the reactor flow path. ${ }^{14}$ To develop a flexible reactor path which could be extended and used with the DrySyn base, we designed circular disk reactors (CDR) which could be placed within the cavities of the DrySyn Multi-E base and additional reactors simply added as required to lengthen the reactor pathway (Figure 2).

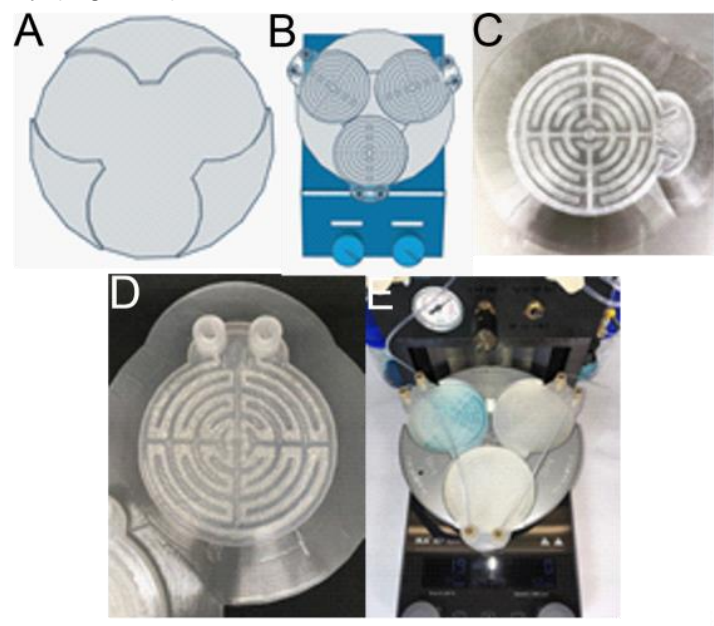

Figure 2. A) Graphical CAD representation of DrySyn Multi-E base; B) Graphical CAD design of DrySyn Multi-E base and three CDRs; C) Part printed CDR showing the flow path; D) Fully PP printed CDR; E) Installed CDRs and linking for a longer flow path.

Reactors were designed using Tinkercad free online software (Autodesk) and incorporated screw-thread adaptors in the design for addition of PEEK fittings. ${ }^{15}$ Reactors were $75 \mathrm{~mm}$ wide (equivalent to the spaces in the DrySyn blocks) and $7 \mathrm{~mm}$ high with an internal $2 \mathrm{~mm}$ high reactor channel (Supplementary Information). Reactors were printed on an Ultimaker 3 3D printer using PP filament at $100 \%$ infill with an internal volume of $4.2 \mathrm{~mL}$.

In order to develop a low-cost continuous flow system, we elected to obviate the use of expensive pumps or syringe pumps and simply control the flow of the system by compressed air. Doyle had previously shown that compressed air could be used to control microfluidics and we were keen to see whether this concept could also be used on the scales typically encountered in synthetic chemistry laboratories, as this would greatly reduce the overall cost of the device and is found in all chemistry fume hoods. In addition, simple replacing of the air with nitrogen gas would mean that reactions could be easily carried out under inert conditions. ${ }^{16}$

In order to attach the system to the stirrer hotplate it was designed with two holes through all sections so that they could be readily fixed on the stands of both IKA and Heidolph stirrer hotplates. The system was composed of a base unit housing the compressed air manifold, a flow control unit containing a needle valve for fine control of the pressure for reactor flow and an injection unit where reagents could be readily added into the flow path via low-pressure 6-position loop injectors. All blocks were designed to be the same size to fit above the stirrer hotplate and the larger solvent holder was placed directly above these and the blocks held down by the metal hotplate rods (Figure 3 ).
A

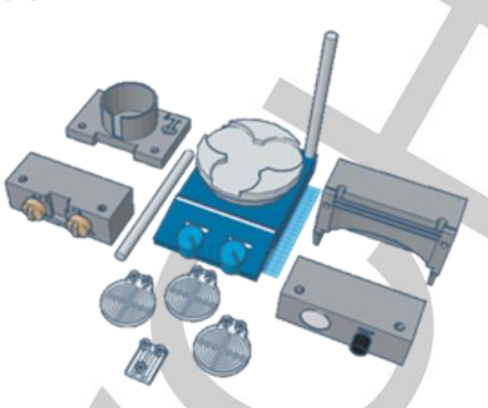

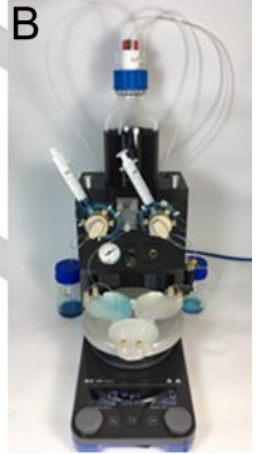

Figure 3. A) Disassembled CAD drawing outlines of the separate continuous flow system components covering the solvent block, injection block, CDRs, mixing chip, flow controller and base block; B) 3D-printed and realised hotplate continuous flow-system combined with circular disk reactors.

In order to use compressed air as the driving force for the system, we decided to use Duran pressure bottles, which can be safely pressurised to 1.5 bar. ${ }^{17}$ All separate reactor blocks were printed at $10 \%$ infill and 0.2 layer height in PLA on an Ultimaker 3 $3 \mathrm{D}$ printer. The two injection valves were connected via a simple 3D printed PP mixing chip at the centre of the injection block (Supplementary Information). Once assembled, the entire system was $341 \mathrm{~mm}$ high prior to addition of the solvent bottle (Figure 3). The separate units of the system and their requisite printing times are listed below, clearly demonstrating the low cost nature of its construction (Table 1).

Table 1. 3D Printed components in the continuous flow system.

\begin{tabular}{|c|c|c|c|c|c|c|}
\hline Entry & Print & Material & $\begin{array}{l}\text { Printed } \\
\text { weight } \\
\text { [g] }\end{array}$ & $\begin{array}{l}\text { Printing } \\
\text { Time } \\
\text { [h] }\end{array}$ & $\begin{array}{l}\text { Cost } \\
{[\$]^{a}}\end{array}$ & $\begin{array}{l}\text { Size } \\
{[\mathrm{mm}]}\end{array}$ \\
\hline 1 & $\begin{array}{l}\text { Base } \\
\text { Block }\end{array}$ & $\mathrm{PLA}^{[\mathrm{a}]}$ & 269 & 20.00 & 18.29 & $\begin{array}{l}180 \times 90 \\
\times 60\end{array}$ \\
\hline 2 & $\begin{array}{l}\text { Base } \\
\text { Cover }\end{array}$ & $\mathrm{PLA}^{[\mathrm{a}]}$ & 27 & 3.29 & 1.84 & $\begin{array}{l}164 \times 74 \\
\times 3\end{array}$ \\
\hline 3 & $\begin{array}{l}\text { Base } \\
\text { Feet }\end{array}$ & $\mathrm{PLA}^{[\mathrm{a}]}$ & 23 & 2.51 & 1.56 & $\begin{array}{l}102 \times 80 \\
x 4\end{array}$ \\
\hline 4 & $\begin{array}{l}\text { Flow } \\
\text { Control }\end{array}$ & $P L A^{[a]}$ & 209 & 14.36 & 14.00 & $\begin{array}{l}180 \times 70 \\
\times 60\end{array}$ \\
\hline 5 & $\begin{array}{l}\text { Flow } \\
\text { Cover }\end{array}$ & $P L A^{[a]}$ & 20 & 2.28 & 1.34 & $\begin{array}{l}155 \times 54 \\
\times 3\end{array}$ \\
\hline 6 & $\begin{array}{l}\text { Injection } \\
\text { Block }\end{array}$ & $P L A^{[a]}$ & 221 & 16.26 & 14.81 & $\begin{array}{l}180 \times 70 \\
\times 60\end{array}$ \\
\hline 7 & $\begin{array}{l}\text { Injection } \\
\text { Cover }\end{array}$ & $\mathrm{PLA}^{[\mathrm{a}]}$ & 32 & 4.22 & 2.14 & $\begin{array}{l}159 \times 55 \\
\times 23\end{array}$ \\
\hline 8 & $\begin{array}{l}\text { Solvent } \\
\text { Block }\end{array}$ & $\mathrm{PLA}^{[\mathrm{a}]}$ & 124 & 9.54 & 8.31 & $\begin{array}{l}180 \times 110 x \\
70\end{array}$ \\
\hline 9 & Mix Chip & $P P^{[b]}$ & 10 & 3.02 & 0.77 & $42 \times 34 \times 17$ \\
\hline 10 & CDR & $P P^{[b]}$ & 25 & 8.41 & 1.93 & $87 \times 75 \times 17$ \\
\hline
\end{tabular}

[a] $750 \mathrm{~g}$ PLA tilament - \$50.75. [b] $750 \mathrm{~g}$ PP tilament - $\$ 57.94$. 
As the planned setup uses constant pressure to deliver fluidic flow and not a constant flow rate, we needed precise control over the pressure gradient applied to the system. Our intended low-cost approach meant that fine pressure control was not easily achievable but, more importantly, would also not allow control of flow rates which change with respect to reactor/device geometry. ${ }^{18}$ Additionally, carrying out reactions at near or above solvent boiling point requires the use of a back pressure regulator (BPR) which would add considerable costs to the system. It would also mean that we would need much higher pressures than recommended for the Duran pressure solvent reservoir. ${ }^{17}$ Inspired by the use of capillary resistors currently used in the field of microfluidics, ${ }^{19}$ we decided to control the hydraulic resistance of our pressure-driven system and the flow rate by altering the pressure applied according to the Hagen-Poiseuille law (Eq. (1)) which can also be simplified to Eq. (2), where $R_{h}$ is the hydraulic resistance.

$$
Q=\frac{\Delta P \pi R^{4}}{8 \mu L}(1) ; \Delta P=Q R_{h}
$$

Equation 1. 1) Hagen-Poiseuille equation; 2) Simplified Hagen-Poiseuille equation.

Based on this equation, we would need to know $R_{h}$ of the whole system were we to control the flow rate. However, if the $R_{h}$ of a capillary resistor is greater than that of the whole system, it can readily regulate the flow rate. ${ }^{19}$ As the flow system uses 1.0 $\mathrm{mm} I D$ tubing and a meso-scale reactor in the use of the CDRs, we envisaged that addition of easily accessible HPLC PEEK tubing would allow us to develop a suitable set of capillary resistors that would offer sufficient resistance and also be compatible with organic solvents obviating the need for back pressure regulators.

Our aim was to have a set of capillaries that would offer the greatest control of the flow rate. In order to test this, we set about predicting the flow rates at different pressures for a given capillary size, solvent $(\mathrm{MeOH})$ and temperature using the Hagen-Poiseuille equation (Eqn. 1). ${ }^{20}$ There needed to be a balance between low response with respect to pressure change - to give the greatest control of flow rate - and a practical flow rate range. We elected to use a set of 5 capillaries that would cover a flow rate range of 0.1-8 $\mathrm{mL} / \mathrm{min}$ (Figure 4 and Supplementary Information).

Capillary 5: $0.25 \mathrm{~mm} \mathrm{ID} \mathrm{x} 90 \mathrm{~mm}$ length (blue)

Capillary 4: $0.18 \mathrm{~mm} \mathrm{ID} \mathrm{x} 60 \mathrm{~mm}$ length (yellow)

Capillary 3: $0.18 \mathrm{~mm}$ ID $\times 120 \mathrm{~mm}$ length (yellow)

Capillary 2: $0.127 \mathrm{~mm} \mathrm{ID} \mathrm{x} 60 \mathrm{~mm}$ length (red)

Capillary 1: $0.127 \mathrm{~mm}$ ID $\times 150 \mathrm{~mm}$ length (red)

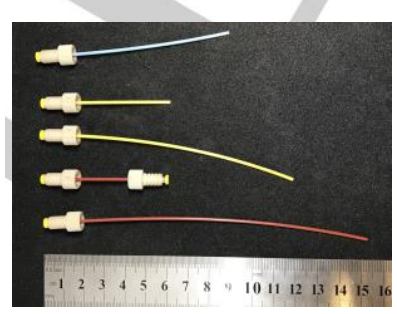

Figure 4. A) Selected capillaries showing the lengths required to provide flow rates ranging from $8 \mathrm{~mL} / \mathrm{min}$ to $0.1 \mathrm{~mL} / \mathrm{min}$.

Pleasingly, when these capillary resistors were tested with our system, we observed excellent control of the flow rate that matched the predicted controls (Figure 5 and Supplementary Information).

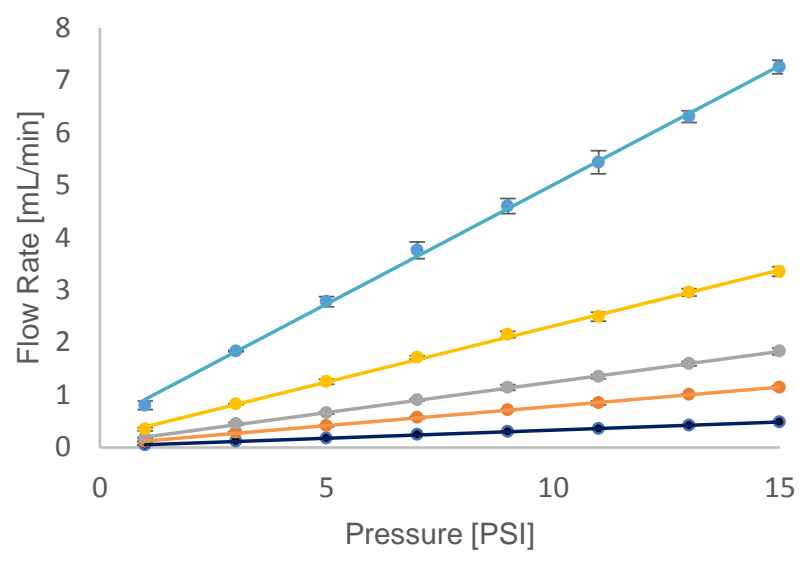

- Capillary 1 - Capillary 2 Capillary $3 \bullet$ Capillary $4 \bullet$ Capillary 5

Figure 5. Measured Flow rates.

The capillaries could be placed either upstream or downstream of the $3 \mathrm{D}$ printed circular disk reactors. However, cognisant of the need to control flow rates when carrying out reactions at elevated temperatures, the capillaries were placed downstream of the reactors to assess its ability to act as a back pressure regulator. The flow rate was unchanged when $\mathrm{MeOH}$ was subjected to $10 \mathrm{PSI}$ at either room temperature or $65^{\circ} \mathrm{C}$ ( $0.127 \mathrm{~mm}$ ID $\times 150 \mathrm{~mm}$ capillary). It should be noted that this ability of the capillary to act as a BPR does not hold for pressures lower than $10 \mathrm{PSI}$ and can result in backwards solvent flow. As long as the pressure gradient is at or above the pressure generated by the heated solvent, flow rates can be predictably controlled. Additionally, as the temperature will be closer to ambient at the capillary (Supplementary Information), any change in viscosity of the solvent at moderate temperatures need not be regarded as significant as the temperature will be closer to ambient at the capillary as it is exposed to airflow and cools rapidly.

With effective control of flow rates and temperatures we next looked at suitable reactions with which to demonstrate the utility of the system. We elected to explore $S_{N} A r$ reactions between 4nitro-2-chloropyridine 1 and 4-methoxyphenol 2 in the presence of DBU in acetonitrile with the 3D printed flow system in the first instance, primarily to exemplify the use of our continuous flow system as $S_{N} A r$ reactions have been widely explored in continuous flow synthesis and are important examples of this technology. 2,21

Reactions were optimised using the 3D printed FlowSyn flow reactor system using a range of capillary tubing to provide an array of flow rate/ residence time, temperatures and number of CDRs and the percentage conversion of the reactions was determined from the ${ }^{1} \mathrm{H}$ NMR spectrum of the crude reaction mixture. The pressure of the system was set at $5 \mathrm{PSI}$ using the needle valve on the flow unit and the flow rates were controlled by selecting the requisite capillary tubing (Scheme 1, Table 1). 


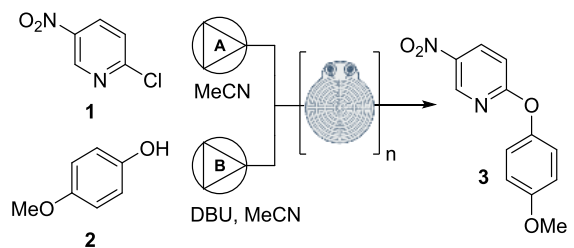

Scheme 1. Reaction conditions selected for exploration of reactor conditions. maintaining the same $0.33 \mathrm{~mL} / \mathrm{min}$ flow rate which increased the yield from $25 \%$ to $47 \%$ for the case of 4 -nitrophenol (Entry 5 , Table 2). Pleasingly, this simple approach led to increased yields of the addition products without adding complex changes to flow rates or temperatures, clearly demonstrating the conceptual simplicity of the additional CDR approach. The extension from 2 to 5 CDRs was achieved by simple addition of a further stirrer hotplate next to the continuous flow system (Supplementary Information).

Table 1. Screening of conditions for the $S_{N} A r$ reaction between 1 and 2.

Table 2. Reaction of a range of alcohols and 2-chloro-5-nitropyridine 1 under

\begin{tabular}{lllllll} 
Entry & $\begin{array}{l}\mathbf{N}^{\circ} \\
\text { CDRs }\end{array}$ & $\begin{array}{l}\text { Capillary } \\
\text { dimensions } \\
\text { (ID x length) } \\
{[\mathrm{mm}]}\end{array}$ & $\begin{array}{l}\text { Pressure } \\
{[\mathrm{PSI}]}\end{array}$ & $\begin{array}{l}\text { Flow } \\
\text { Rate } \\
{[\mathrm{mL} / \mathrm{mi}} \\
\mathrm{n}]\end{array}$ & $\begin{array}{l}\text { Temp } \\
{\left[{ }^{\circ} \mathrm{C}\right]}\end{array}$ & $\begin{array}{l}\text { Conv. } \\
{[\%]^{[\mathrm{a}]}}\end{array}$ \\
\hline 1 & 1 & $0.12 \times 60$ & 5 & 0.80 & $\mathrm{rt}$ & 45 \\
2 & 1 & $0.12 \times 60$ & 5 & 0.80 & 50 & 69 \\
3 & 1 & $0.12 \times 60$ & 5 & 0.84 & 65 & 74 \\
4 & 2 & $0.12 \times 60$ & 5 & 0.84 & 65 & 88 \\
5 & 2 & $0.12 \times 150$ & 5 & 0.33 & 65 & 95
\end{tabular}

From the experiments, it was clear that the printed reactors were able to facilitate the reaction and that the flow rates allowed facile control over the residence time of the reactants. Cognisant of the insulating properties of polypropylene, the CDRs were preheated for 10 minutes prior to carrying out the reaction as in previous research. ${ }^{12} \mathrm{~A}$ solution of 2-chloro-5-nitropyridine 1 in acetonitrile was injected in injection port $A$ and 4-methoxyphenol 2 and DBU in acetonitrile via injection port B using the injection loops. Following screening, it was shown that the use of a 0.12 $\mathrm{mm} \times 150 \mathrm{~mm}$ capillary and a temperature of $65^{\circ} \mathrm{C}$ gave an excellent yield of the addition product 3 using 2 CDRs in sequence on the stirrer hotplate which gave the product in $95 \%$ conversion. Having optimised the reaction, we next investigated the reaction with a range of alcohols 4 to ensure that the reaction setup was sufficient for a range of substrates as shown below (Scheme 2 and Table 2).

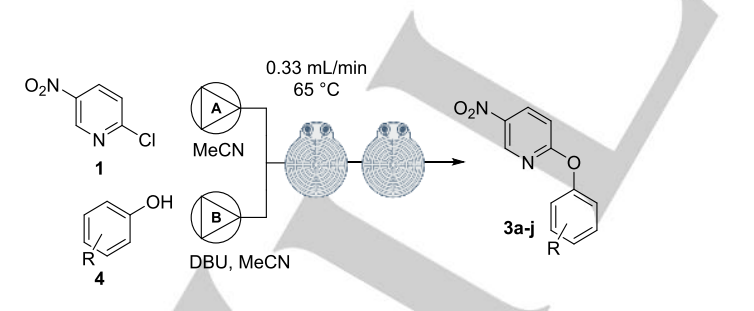

Scheme 2. SNAr reaction between 3 and a range of alcohols.

Following the screening of a range of alcohols, it was evident that the $3 \mathrm{D}$ printed continuous flow system was able to facilitate the formation of a range of ether derivatives and most compounds gave good to excellent conversions and isolated yields of the addition product. Use of 2 CDRs for the reaction led to lower yields of the addition products in the case of 4-nitrophenol (Entry 4, Table 2) and 2,2,2-trifluoroethanol (Entry 8, Table 2) and 4-methylparaben. In order to increase the yield obtained, the path length was increased by simply increasing the number of disk reactors from 2 to 5 , extending the retention time at $65^{\circ} \mathrm{C}$ whilst

\begin{tabular}{|c|c|c|c|c|c|}
\hline Entry & Alcohol[a] & $\begin{array}{l}\mathrm{N}^{\circ} \\
\text { CDRs }\end{array}$ & Product & $\begin{array}{l}\text { Conv. } \\
{[\%]^{[b]}}\end{array}$ & $\begin{array}{l}\text { Yield } \\
{[\%]}\end{array}$ \\
\hline 1 & 4-methoxyphenol & 2 & $3 a$ & 95 & 94 \\
\hline 2 & phenol & 2 & $3 b$ & 92 & 84 \\
\hline 3 & p-cresol & 2 & $3 c$ & 91 & 87 \\
\hline 4 & 4-nitrophenol & 2 & $3 d$ & 25 & - \\
\hline 5 & 4-nitrophenol & 5 & $3 d$ & 47 & 23 \\
\hline 6 & 4-fluorophenol & 2 & $3 e$ & 97 & 96 \\
\hline 7 & 4-bromophenol & 2 & $3 f$ & 97 & 82 \\
\hline 8 & $\begin{array}{l}2,2,2- \\
\text { trifluoroethanol }\end{array}$ & 2 & $3 g$ & 40 & - \\
\hline 9 & $\begin{array}{l}2,2,2- \\
\text { trifluoroethanol }\end{array}$ & 5 & $3 g$ & 47 & 18 \\
\hline 10 & 4-methylparaben & 2 & $3 h$ & 46 & 41 \\
\hline 11 & 4-chlorophenol & 2 & $3 \mathbf{i}$ & 97 & 71 \\
\hline 12 & $m$-cresol & 2 & $3 \mathbf{j}$ & 94 & 68 \\
\hline
\end{tabular}

[a] Reactions were carried out at $65^{\circ} \mathrm{C}$ and a flow rate of $0.33 \mathrm{~mL} / \mathrm{min}$. [b] Determined by ${ }^{1} \mathrm{H}$ NMR analysis of the crude reaction mixture.

\section{Conclusions}

In conclusion, we have designed, developed and 3D printed a low-cost continuous flow system that is able to be integrated with existing stirrer hotplates and whose flow is powered and controlled by compressed air. The system uses 3D printed circular disk reactors whose pathlength can easily be extended and linked to create a range of flow path volumes with facile control of the residence time by the simple expedient of using resistance capillary tubing. This approach will enable synthetic chemists to carry to flow chemistry at low-cost and using existing laboratory and fume hood equipment without having to invest in expensive and large continuous flow equipment. Further studies on additional reactors and reaction chemistries are currently under way in our laboratory and will be reported in due course. 


\section{Acknowledgements}

We thank Asynt Ltd. and Uniqsis Ltd. for their material support.

Keywords: 3D-printing, continuous-flow, reactionware, polypropylene, heterocycles.

[1] a) C. W. Hull, 1986, US4575330; b) B. C. Gross, J. L. Erkal, S. Y Lockwood, C. Chen, D. M. Spence, Anal. Chem. 2014, 86, 3240 3253; c) S. Rossi, A. Puglisi, M. Benaglia, ChemCatChem 2018, 10 1512-1525; d) A. J. Capel, R. R. Rimington, M. P. Lewis, S. D. R Christie, Nat. Rev. Chem. 2018, 2, 422-436; e) A. Bédard, A. Adamo, K. C. Aroh, M. G. Russel, A. A. Bedermann, J. Torosian ,B Yue, K. F. Jensen, T. F. Jamison, Science 2018, 361, 1220-1225; f) R. Gérardy, N. Emmanuel, T. Toupy, V. Kassin, N. N. Tshibalonza, M. I. Schmitz, J. M. Monbalio, Eur. J. Org. Chem. 2018, 2301-2351. a) R. Porta, M. Benaglia, A. Puglisi, Org. Process Res. Dev. 2016 20, 2-25; b) N. Bhattacharjee, A. Urrios, S. Kang, A. Folch, Lab Chip 2016, 16, 1720-1742; c) J. H. Bannock, S. H. Krishnadasan, M. Heeney, J. C. de Mello, Mater. Horiz., 2014, 1, 373-378; d) I. Rossetti, Catalysis Today 2018, 20-31; e) M. B. Plutschack, B. Pieber, K. Gilmore, P. H. Seeberger, Chem. Rev. 2017, 117, 1179611893.

a) Y. Zhang, S. Ge, J. Yu, Trends Anal. Chem. 2016, 85, 166-180 b) G. W. Bishop, J. E. Satterwhite, S. Bhakta, K. Kadimisetty, K. M. Gillete, E. Chen and J. F. Rusling, Anal. Chem. 2015, 87, 54375443; c) A. Ambrosi, M. Pumera Chem. Soc. Rev. 2016, 45, 27402755; d) P. J. Kitson, S. Glatzel, W. Chen, C. -G. Lin, Y. -F. Song, L. Cronin, Nature Protocols 2016, 11, 920-936.

[4] a) F. Lederle, F. Meyer, C. Kaldun, J. C. Namyslo and E. G. Hübner, New J. Chem. 2017, 41, 1925-1932; b) F. Lederle, C. Kaldun, J. C. Namyslo and E. G. Hübner, Helv. Chim. Acta 2016, 99, 255-266; c) F. Lederle, F. Meyer, G.-P. Brunotte, C. Kaldun and E. G. Hübner, Prog. Addit. Manuf. 2016, 1, 3-7; d) E. G. Gordeev, E. S Degtyareva, V. P. Ananikov, Russ. Chem. Bull. Int. Ed. 2016, 65, 1637-1643.

[5] a) R. D. Johnson, Nature Chem. 2012, 4, 338-339; b) I. D. Williams Nature Chem. 2012, 4, 953-954.

[6] a) A. J. Capel, S. Edmondson, S. D. R. Christie, R. D. Goodridge, R. J. Bibb, M. Thurstans, Lab Chip 2013, 13, 4583-4590; b) G. Scotti, S. M. E. Nilsson, M. Haapala, P. Pöhö, G. B. Gennäs, J. YliKauhaluoma, T. Kotiaho, React. Chem. Eng. 2017, 2, 299-303; c) D. E. Fitzpatrick, C. Battilocchio, S. V. Ley, ACS Cent. Sci. 2016, 2, 131-138; d) N. Bhattacharjee, A. Urrios, S. Kang, A. Folch, Lab Chip 2016, 16, 1720-1742.

[7] a) P. K. Yuen, Lab Chip 2016, 16, 3700-3707; b) V. Sans, L. Porwol, V. Dragone, L. Cronin, Chem. Sci. 2015, 6, 1258-1264; c) J. S. Mathieson, M. H. Rosnes, V. Sans, P. J. Kitson, L. Cronin, Beilstein J. Nanotechnol. 2013, 4, 285-291; d) S. Rossi, R. Porta, D. Brenna, A. Puglisi, M. Benaglia, Angew, Chem. Int. Ed. 2017, 56, 4290-4294.

[8] F. M. Akwi, P. Watts, Chem. Commun. 2018, 54, 13894-13928.

[9] a) P. J. Kitson, G. Marie, J. Francoia, S. S. Zalesskiy, R. C Sigerson, J. S. Mathieson, L. Cronin, Science 2018, 359, 314-319; b) P. J. Kitson, S. Glatzel, L. Cronin, Beilstein J. Org. Chem. 2016 12, 2776-2783; c) P. J. Kitson, M. D. Symes, V. Dragone, L. Cronin,
Chem. Sci. 2013, 4, 3099-3103; d) V. Dragone, V. Sans, M. H. Rosnes, P. J. Kitson, L. Cronin, Beilstein J. Org. Chem. 2013, 9 951-959; e) P. J. Kitson, M. H. Rosnes, V. Sans, L. Cronin, Lab Chip 2012, 12, 3267-3271; f) M. D. Symes, P. J. Kitson, JU. Yan, C. J. Richmond, G. J. T. Cooper, R. W. Bowman, T. Vilbrandt, L. Cronin Nature Chemistry 2012, 4, 349-354; g) P. J. Kitson, R. J. Marshall, D. Long, R. S. Forgan, L. Cronin, Angew. Chem. Int. Ed. 2014, 53, 12723-12728.

[10] A. J. Capel, A. Wright, M. J. Harding, G. W. Weaver, Y. Li, R. A Harris, S. Edmondson, R. D. Goodridge, S. D. R. Christie, Beilstein J. Org. Chem. 2017, 13, 111-119.

[11] B. Gutmann, M. Köckinger, G. Glotz, T. Ciaglia, E. Slama, M Zadravec, S. Pfanner, M. C. Maier, H. Gruber-Wölfler, C. O. Kappe, React. Chem. Eng. 2017, 2, 919-927.

[12] ZX. Rao, B. Patel, A. Monaco, Z.J. cao, M. Barniol-Xicota, E. Pichon, M. Ladlow, S.T. Hilton, Eur. J. Org. Chem. 2017, 6499-6504.

[13] a) S. K. Talapatra, M. R. Penny, S. T. Hilton, F. Kozielski, J. Appl. Cryst. 2019, 52, 171-174; b) B. C. Sil, M. P. Alvarez, Y. Zhang, C. P Kung, M Hossain, F lliopoulos, L Luo, J M. Crowther, D J. Moore, J. Hadgraft, M. E Lane and S. T. Hilton, Int J. Cosmet Sci. 2018, 40, 604-609; c) Z. Muwaffak, A. Goyanes, V. Clark, A. W. Basit, S. Gaisford, S. T. Hilton, Int. J. Pharm. 2017, 527, 161-170; d) M. Penny, Z. Jing Cao, B. Patel, B. Sil dos Santos, C. Asquith, B. R. Szulc, Z. X. Rao, Z. Muwaffak, J. P. Malkinson and S. T. Hilton, J. Chem. Ed. 2017, 94, 1265-1271; e) A. Mohammed, M. E. Vianna, S. T. Hilton, D. R. Boniface, Y-L. Ng, J. C. Knowles, Microsc. Res. Tech. 2017, 80, 202-210; f) S. A. Mohammed, M.E. Vianna, M. R. Penny, S. T. Hilton, N. Mordan, J. C. Knowles, Dent. Mater. 2016, 32, 1289-1300; g) A. L. Tyson, S. T. Hilton, L. C. Andreae, Int. J. Pharm. 2015, 494, 651-656.

[14] DrySyn MULTI-E base, https://www.asynt.com/product/drysyn multi-e/, accessed 24 February 2019.

[15] Tinkercad design software, https://www.tinkercad.com/, accessed 24 February 2019

[16] K. W. Bong, S. C. Chapin, D. C. Pregibon, D. Baah, T. M. Floyd Smith, P. S. Doyle, Lab Chip 2011, 11, 743-747.

[17] Duran pressure bottle, http://www.duran-group.com/en/productssolutions/laboratory-glassware/products/laboratory-glassbottles/pressure-plus-laboratory-bottle.html, accessed 24 February 2019.

[18] N. Aoki, K. Mae, Chem. Eng. J. 2006, 189-197.

[19] N. Mavrogiannis, M. Ibo, X. Fu, F. Crivellari, Z. Gagnon, Biomicrofluidics 2016, 10, 034107.

Biomicrofluidics 2016, 10,034107
Flow calcualtor,

https://www.dolomitemicrofluidics.com/support/microfluidic-calculator/, accessed 24 February 2019

[21] a) J. F. Bunnett, R. E. Zahler, Chem. Rev. 1951, 49, 273-412; b) J. F. Bunnett, J. Chem. Educ. 1974, 51, 312-315; c) M. P. Alam, B. Jagodzinska, J. Campagna, P. Spilman, V. John, Tetrahedron Lett. 2016, 57, 2059-2062. 
Entry for the Table of Contents (Please choose one layout)

Layout 2:

\section{COMMUNICATION}
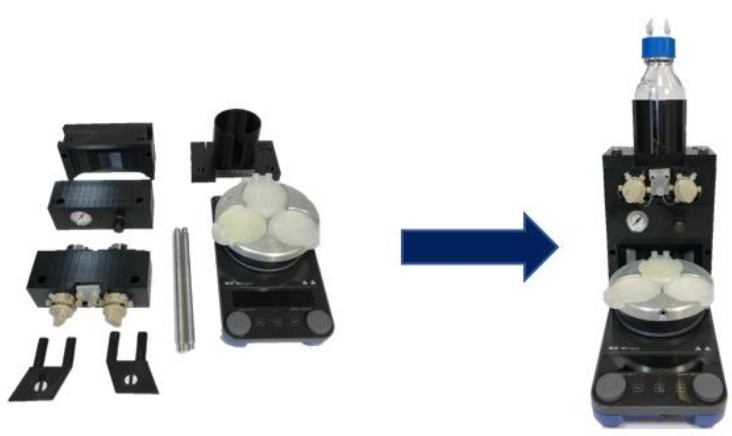

3DPrinting Continuous-Flow

Matthew R. Penny ${ }^{[a]}$, Zenobia Rao[a], Bruno Felício Peniche ${ }^{[b]}$, Stephen $T$. Hilton ${ }^{\star[a]}$ Author(s), Corresponding Author(s)*

Page No. - Page No.

Modular 3D Printed Compressed Air Driven Continuous-Flow Systems for Chemical Synthesis

A low-cost, small-footprint, modular 3D printed continuous-flow system was developed that could be attached to existing stirrer hotplates. Flow-rates are controlled by compressed air typically present in all fume hoods, making it suitable for use by synthetic chemists. The length of the flow-path and reaction residence time is regulated by 3D printed polypropylene (PP) circular disk reactors and the ease of use of the system was demonstrated in a range of $S_{N} A r$ reactions to produce substituted ether derivatives highlighting the utility and modularity of the system. 